\title{
Oligoclonal Expansion of HIV-specific Cytotoxic CD8T Lymphocytes in the Skin of HIV-1-infected Patients with Cutaneous Pseudolymphoma
}

\author{
Hervé Bachelez, ${ }^{\ddagger}$ Fabienne Hadida, ${ }^{*}$ Christophe Parizot, ${ }^{\star}$ Béatrice Flageul, ${ }^{\ddagger}$ Mathilde Kemula, ${ }^{\star \ddagger}$ Louis Dubertret, ${ }^{\ddagger}$ \\ Patrice Debree, ${ }^{*}$ and Guy Gorochov* \\ *Laboratoire d'Immunologie, Hôpital de la Pitié-Salpétrière, 75013 Paris, France; and ${ }^{\ddagger}$ Institut de Recherche sur la Peau, Hôpital \\ Saint-Louis, 75010 Paris, France
}

\begin{abstract}
A massive infiltration of the skin by activated CD8 + T lymphocytes involving both the dermis and the epidermis has been found in HIV-1-infected patients presenting with a chronic skin rash. We characterized the $T$ cell receptor (TCR) BV-BJ junctional diversity of the skin-infiltrating lymphocytes (SILs) in four patients. The SILs expressed a limited set of TCRBV gene segments. Complementarity determining region 3 length analysis further emphasized their oligoclonality, suggesting that antigen stimulation might be responsible for the cutaneous $T$ cell expansion. Furthermore, independent skin biopsies obtained from the same individual were shown to harbor distinct $T$ cell repertoires, possibly reflecting the spatial heterogeneity of the antigenic stimuli. The CD8 + cytotoxic T lymphocyte (CTL) lines isolated from the skin rash in one patient exhibited a specific, class I MHC-restricted cytotoxic activity against HIV-1 Gag- and Pol-expressing target cells, whereas CTL lines derived from the skin lesions of a second patient were shown to be predominantly Env-specific. Taken together, these data demonstrate the infiltration of HIV-specific CTLs in the skin of HIV-infected patients, and suggest that in addition to their known role in controlling the retroviral infection, these CTLs may also be involved in the pathogenesis of cutaneous inflammatory disorders occurring during the course of HIV infection. (J. Clin. Invest. 1998. 101:25062516.) Key words: HIV-1 - cytotoxic T lymphocyte $\cdot \mathrm{T}$ cell receptor $\mathrm{BV} \bullet$ repertoire $\bullet$ rash
\end{abstract}

\section{Introduction}

CD8+ cytotoxic T lymphocytes (CTLs) ${ }^{1}$ play a key role in the defense against intracellular pathogens $(1,2)$. In mice, virusspecific CTLs have been shown to be involved in the eradication of respiratory syncytial virus (3), whereas in humans, virus-specific CTL activity protects against influenza (4). After

Address correspondence to Dr. Guy Gorochov, Laboratoire d'Immunologie Cellulaire, CERVI, CNRS UMR 7627, Hôpital de la PitiéSalpétrière, 83 Boulevard de l'Hôpital, 75013 Paris, France. Phone: 33-1-421-77507; FAX: 33-1-421-77490; E-mail: guy.gorochov@psl.aphop-paris.fr

Received for publication 8 August 1997 and accepted in revised form 23 March 1998.

J. Clin. Invest.

(C) The American Society for Clinical Investigation, Inc. 0021-9738/98/06/2506/11 \$2.00

Volume 101, Number 11, June 1998, 2506-2516

http://www.jci.org primary HIV infection, oligoclonal expansion of HIV-specific CTLs can be detected in the peripheral blood (5). Moreover, extensive studies have documented a CTL response against viral peptides derived from structural or regulatory HIV proteins, in the blood (6-8) and in the lymphoid organs (9-11) of HIV-infected patients. Although specific cytotoxic cells fail to eliminate all HIV-infected cells, they are widely believed to be essential to the control of HIV replication during the asymptomatic phase of HIV infection, by killing infected cells before virion release (12).

The antiviral immune response can also cause local tissue damage, as has been demonstrated for the brain lesions of mice infected with the lymphocytic choriomeningitis virus (13), and for the liver necrosis of hepatitis B virus-infected humans (14). In a similar way, the contribution of a specific CTL response to other sequelae during viral infection has been suggested in patients affected by HIV-related lymphocytic alveolitis (6), and in simian immunodeficiency virus (SIV)-infected rhesus monkeys presenting with skin eruption (15).

Recently, a new disease entity consisting of a chronic severe skin disorder characterized by extensive plaque lesions or erythroderma has been reported in patients with AIDS (16, 17). In patients presenting with this syndrome, histopathological examination of skin biopsies revealed a dense $\mathrm{T}$ cell infiltration of the dermis, with or without epidermal involvement (18). Although these morphological findings may be suggestive of a cutaneous T cell lymphoma (CTCL), i.e., mycosis fungoïdes or Sézary syndrome, results from immunophenotypic studies of the skin infiltrate and from clonality assays have shown major differences from CTCLs occurring in HIVseronegative patients (16-18). First, the tumoral cells in "classical" CTCL usually exhibit a CD4 T helper phenotype (19), whereas dermal and epidermal lymphocytes in HIV-associated cutaneous pseudolymphoma express predominantly the CD8 antigen (16-18). Furthermore, whereas CTCLs result from the monoclonal proliferation of malignant lymphocytes $(20,21)$, molecular genetic studies in AIDS-associated CTCL-like disease failed to detect any dominant monoclonal subset $(16,19)$, thus questioning the neoplastic nature of these lymphoproliferations.

In this study, we analyzed the repertoire of BV segments used by skin-infiltrating CD8 cells in four HIV-infected pa-

1. Abbreviations used in this paper: $\mathrm{CDC}$, Center for Disease Control; CDR3, complementarity-determining region 3; CLA, cutaneous lymphocyte-associated antigen; CTL, cytotoxic T lymphocyte; CTCL, cutaneous T cell lymphoma; LC, Langerhans cell; PE, phycoerythrin; RT, reverse transcriptase; SIL, skin-infiltrating lymphocyte; SIV, simian immunodeficiency virus; TCR, T cell receptor; VAC-ENV, -GAG, -NEF, and -POL, recombinant vaccinia virus expressing HIV-1 LAI gp160, HIV-1 LAI Gag, HIV-1 LAI Nef, and HIV-1 LAI Pol; VACWT, wild-type vaccinia virus, Copenhagen strain. 
Table I. Clinical Profile, and Immunological and Virological Status in the Four HIV-infected Patients

\begin{tabular}{|c|c|c|c|c|c|c|}
\hline \multirow[b]{2}{*}{ Patient } & \multirow[b]{2}{*}{ Age/sex } & \multirow[b]{2}{*}{ CDC stage } & \multicolumn{2}{|c|}{ PBMC counts } & \multirow[b]{2}{*}{ p24 antigenemia } & \multirow[b]{2}{*}{ Viral load* } \\
\hline & & & $\mathrm{CD} 4$ & CD8 & & \\
\hline \multicolumn{6}{|c|}{ cells $/ \mu l$ cells $/ \mu l$} & copies $/ m l$ \\
\hline A & $32 / \mathrm{M}$ & A & 450 & 1800 & Negative & 1500 \\
\hline B & $43 / \mathrm{M}$ & B & 5 & 523 & Negative & 23500 \\
\hline $\mathrm{C}$ & $62 / \mathrm{M}$ & $\mathrm{C}$ & 14 & 464 & Positive $(225 \mathrm{pg} / \mathrm{ml})$ & ND \\
\hline $\mathrm{D}$ & $50 / \mathrm{M}$ & $\mathrm{C}$ & 4 & 221 & ND & 9700 \\
\hline
\end{tabular}

* Measured in the patients' serum using HIV RNA-specific RT-PCR (Amplicor test). ND, Not determined.

tients affected by this syndrome. Our analysis of the T cell receptor (TCR) $\beta$ junctional sequences strongly suggest a complementarity-determining region 3 (CDR3)-dependent cutaneous expansion of particular BV segments. We further examined the functional profiles of CD8+ cell lines derived from the skin of two patients. These studies showed that these lines were involved in a specific, HLA class I-restricted cytotoxic recognition of HIV antigens.

\section{Methods}

Patients. The study was performed after obtaining the informed consent of four HIV-1-infected male patients presenting with a chronic erythrodermic cutaneous disorder. The immunological status and virological parameters obtained in these patients at the time of diagnosis of skin disease are listed in Table I. Patients did not receive any therapy at the time of onset of skin lesions, which consisted initially of erythrosquamous plaques, progressively resulting in erythroderma. Pigmented lesions developed in patients $\mathrm{A}, \mathrm{B}$, and $\mathrm{C}$ during the course of the disease (Fig. 1). Skin symptoms followed a chronic course, their duration lasting from $<6$ mo to $2 \mathrm{yr}$ before this study.
All patients received topical corticosteroids without efficacy before the study, and patient A also received Psoralen photochemotherapy (PUVA therapy), which led to a worsening of skin symptoms. Local corticosteroid therapy was stopped at least $15 \mathrm{~d}$ before skin biopsies. Histopathological analysis of skin biopsies revealed in all cases a dense dermal infiltration by $\mathrm{T}$ cells, together with epidermal exocytosis. In some biopsies, cytonuclear irregularities were observed thoughout the skin infiltrate, supporting the diagnosis of CTCL-like infiltration of the skin (18). In all biopsies, dermal and epidermal infiltrating lymphocytes exhibited exclusively a mature CD8+ CD4phenotype. In patient A, histopathological examination of a biopsy taken from an enlarged cervical lymph node, performed 3 mo after the diagnosis of skin disease, showed an interfollicular hyperplasia, without evidence of lymphoma. Patient A was classified in group A according to the Center for Disease Control (CDC) criteria (22); patient B was CDC group B (oral hairy leucoplakia and oral candidiasis); and patients C and D were CDC group C (Pneumocystis carinii pneumonia/Toxoplasma gondii infection and Mycobacterium tuberculosis infection, respectively) (Table I). Control patients $\mathrm{E}$ and $\mathrm{F}$ were two HIV-1-infected asymptomatic patients showing CD4 cell counts of 423 and 254 cells/ml and CD8 cell counts of 678 and 602 cells $/ \mathrm{ml}$, respectively.

Immunohistochemistry. Immunohistochemical staining of skin punch biopsies and of the lymph node biopsy was performed on frozen sections using a standard avidin-biotin immunoperoxidase procedure described previously (23), with the mAbs anti-CD3, -CD4,-CD8, -CD2, -CD5, -CD7, -HLA DR, -CD38, -CD16, -CD56, -CD57 (Immunotech, Marseille, France); 1C1 (anti-BV5.2/5.3), W112 (antiBV5.3), OT145 (anti-BV6.7), 16G8 (anti-BV8), SS11 (anti-BV12), LC4 (anti-BV5.1) (all anti-TCR $\beta$ chains from $T$ Cell Sciences, Inc., Cambridge, MA); HECA-452 (anti-cutaneous lymphocyte-associated antigen [CLA]; PharMingen, San Diego, CA); and Kal-1 (antiHIV-1 capsid protein p24; DAKO Corp., Carpinteria, CA).

Flow cytometry. For double-fluorescence analysis of T cell lines and PBMCs, cells were stained with the following mAbs: phycoerythrin (PE)-conjugated anti-CD8, PE-conjugated anti-CD4 (Immunotech), FITC-conjugated anti-CD4, and FITC-conjugated anti-CLA (PharMingen). For each sample, $10^{5}$ cells were incubated for $20 \mathrm{~min}$ at $4^{\circ} \mathrm{C}$, washed with PBS, fixed with $2 \%$ paraformaldehyde in PBS, and analyzed on a FACScan ${ }^{\circledR}$ flow cytometer (Becton Dickinson, San

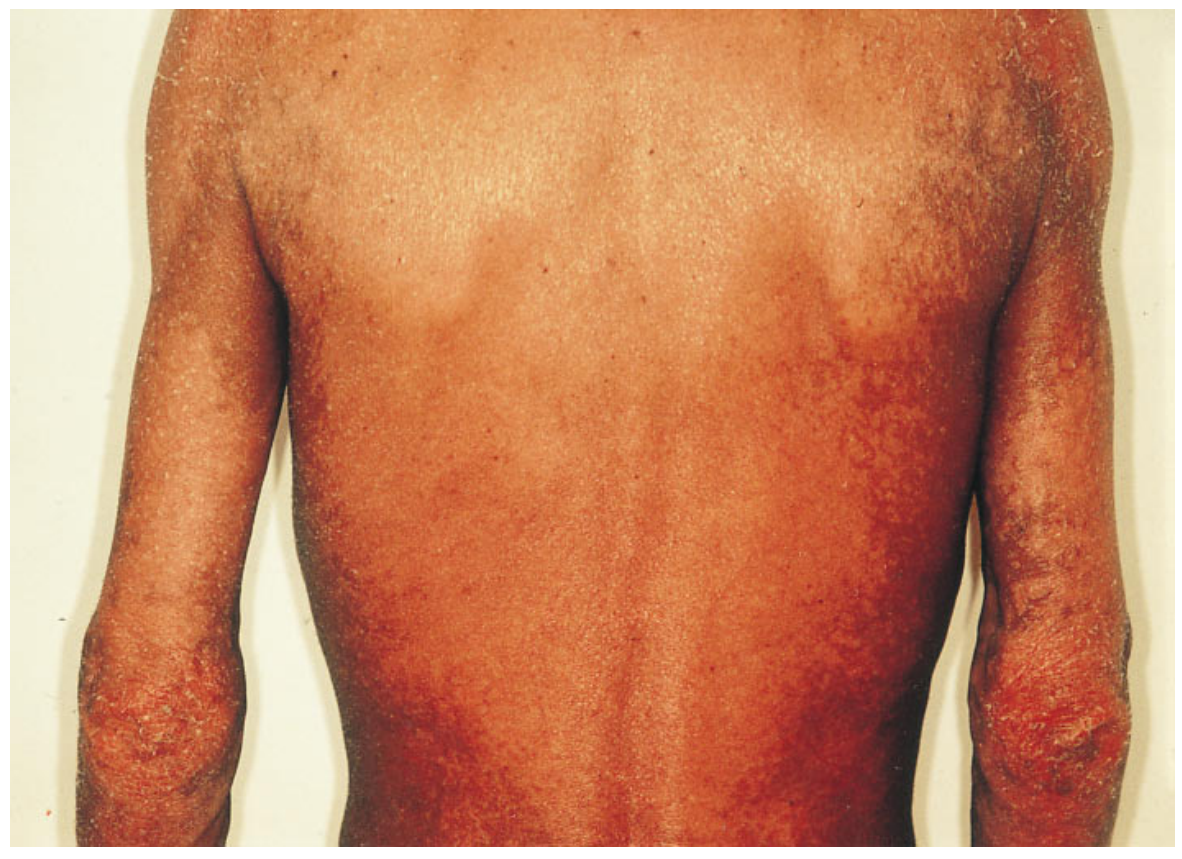

Figure 1. Infiltrated erythroderma with pigmented lesions on the dorsal area of patient A. 
Jose, CA). 10,000 events per sample were collected and analyzed using Cellquest software (Becton Dickinson).

Analysis of the repertoire of TCRBV genes. The TCRBV repertoire was analyzed by a semiquantitative PCR assay as described previously (24). Briefly, total RNA was extracted from cells (skin biopsies, purified CD8+ PBMCs, CD8 + cell lines) by the method of Chomczynski and Sacchi (25). $8 \mu \mathrm{g}$ of RNA was reverse transcribed in a $50-\mu$ l reaction volume using the reagents provided in the Stratascript reverse transcription (RT) PCR kit (Stratagene, La Jolla, CA) according to the manufacturer's instructions. A C $\beta 1$ and $C \beta 2-$ specific 3' oligonucleotide, 5'-CGGGCTGCTCCTTGAGGGGCTGCG-3', and 1 of 24 different BV family-specific oligonucleotides (26) were used, together with a primer pair specific for the TCR C $\alpha$ chain (27) as an internal PCR control. $2 \mu \mathrm{l}$ of the RT product was incubated in a final reaction volume of $50 \mu \mathrm{l}$ containing $10 \mathrm{mM}$ Tris- $\mathrm{HCl}, 1.5 \mathrm{mM}$ $\mathrm{MgCl}_{2}, 50 \mathrm{mM} \mathrm{KCl}, \mathrm{pH} 8.3,20 \mathrm{pmol}$ of each oligonucleotide, $0.2 \mathrm{mM}$ of each dNTP, and 2.5 U of Taq DNA polymerase (Boehringer Mannheim, Mannheim, Germany) which had been blocked for "hot start" with $1.1 \mu \mathrm{g}$ of TaqStart antibody (Clontech, Palo Alto, CA). After an initial denaturation step of $3 \mathrm{~min}$ at $95^{\circ} \mathrm{C}$, the reactions were subjected to 30 cycles of PCR $\left(94^{\circ} \mathrm{C}\right.$ for $30 \mathrm{~s}, 60^{\circ} \mathrm{C}$ for $1 \mathrm{~min}, 74^{\circ} \mathrm{C}$ for 1 $\mathrm{min}$ ), followed by a final extension step of $5 \mathrm{~min}$ at $74^{\circ} \mathrm{C}$. PCR products were analyzed on $2 \%$ agarose gels containing $0.5 \mu \mathrm{g} / \mathrm{ml}$ ethidium bromide. The bands were visualized on an ultraviolet (UV) light box and photographed using a computerized image capture system (Image Store 5000; UVP Ltd., Cambridge, UK). Specificity of amplification was assessed by Southern blot, after transfer on nylon membranes and probing with a ${ }^{32} \mathrm{P}$-end-labeled $\mathrm{C} \beta$-specific internal oligonucleotide (27). Specific signals were quantified by scanning membranes using a Parallel Plate Avalanche Charpak chamber ( $\beta$ Imager 1200; Biospace Instruments, Thoiry, France) and $\beta$-Vision software (Biospace Instruments). Results are expressed for each BV family as a percentage of the sum of all $24 \mathrm{BV}$ family signals measured.

Run-off reactions. One nested C $\beta$ primer, 5'-GTGCACCTCCTTCCCATTCA-3', was dye-labeled (Joe Fluorophore; Applied Biosystems, Inc., Foster City, CA) and used in run-off reactions. $2 \mu \mathrm{l}$ of the PCR product was added to $8 \mu \mathrm{l}$ of a mixture containing $10 \mathrm{mM}$ Tris- $\mathrm{HCl}, 1.5 \mathrm{mM} \mathrm{MgCl} 2,50 \mathrm{mM} \mathrm{KCl}, \mathrm{pH} 8.3,0.2 \mathrm{mM}$ of each dNTP, $0.5 \mathrm{U}$ of Taq DNA polymerase, and $0.1 \mu \mathrm{M}$ of the Joe-labeled C $\beta$ oligonucleotide. The extension reaction consisted of a 3-min denaturation step at $95^{\circ} \mathrm{C}$ followed by 12 cycles of $30 \mathrm{~s}$ at $94^{\circ} \mathrm{C}, 30 \mathrm{~s}$ at $60^{\circ} \mathrm{C}$, and $2 \mathrm{~min}$ at $72^{\circ} \mathrm{C}$. A final 10 -min incubation at $72^{\circ} \mathrm{C}$ was performed.

Electrophoresis and quantitative analysis of TCR CDR3 lengths. $10 \mu \mathrm{l}$ of a $5: 1$ mixture of formamide and $50 \mathrm{mg} / \mathrm{ml}$ dextran blue $/ 25 \mathrm{mM}$ EDTA ( $\mathrm{pH} \mathrm{8.0)} \mathrm{were} \mathrm{added} \mathrm{to} \mathrm{the} 10 \mu \mathrm{l}$ run-off product. $2 \mu \mathrm{l}$ of this mixture was loaded on a $4 \%$ acrylamide $/ 4 \mathrm{M}$ urea sequencing gel and run on a DNA sequencer (ABI 377; Applied Biosystems, Inc.). A mixture of dye-labeled size standards was also loaded on the sequencing gel to allow precise determination of the sizes of the BC-BV or $\mathrm{BC}-\mathrm{BJ}$ run-off reaction products. The size and area of the peaks corresponding to the DNA products were determined using the Immunoscope software package (version 3.01c; C. Pannetier, Pasteur Institute, Paris, France). The observed peaks are usually separated by three bases and correspond to in-frame transcripts of TCRs. Windows of analysis were centered on expected sizes corresponding to TCR transcripts encoding a 10-amino acid-long CDR3. The CDR3 region was defined according to Kabat et al. (28).

Cloning and sequencing of $P C R$ products. BV amplicons of interest were gel purified and ligated directly into the $\mathrm{PCR}^{\circledR} \mathrm{II}$ vector (TA cloning kit; Invitrogen Corp., San Diego, CA). After amplification into Escherichia coli, plasmids were purified, and their inserts were sequenced using an automated sequencer with M13 rev and T7 dyelabeled primers and Amplitaq DNA polymerase FS (Applied Biosystems, Inc.).

Target cells. An EBV-transformed B lymphoblastoid cell line (B-LCL) was established from PBMCs isolated from patient A and expanded in RPMI 1640 supplemented with $10 \%$ FCS, L-glutamine, penicillin $100 \mathrm{U} / \mathrm{ml}$, and streptomycin $100 \mu \mathrm{g} / \mathrm{ml}$. B-LCL cells derived from healthy donors and selected for HLA antigens matched with the patients were also used as target cells. B-LCL cells were infected with recombinant vaccinia virus constructs expressing different HIV gene products, at an moi of $5 \mathrm{PFU}$ per cell. Recombinant vaccinia virus constructs included the wild-type Copenhagen strain (VAC-WT) and various recombinants encoding either the Gag (VAC-GAG), Env (VAC-ENV), Pol (VAC-POL), or Nef (VAC-NEF) antigens of the HIV-1 LAI isolate (Transgène, Strasbourg, France) $(29,30)$.

Effector cells. Skin lymphocytes were isolated from two patients as described previously (31). Briefly, a 5-mm punch skin biopsy was rinsed and minced gently with scissors in RPMI 1640 medium (ICN Biomedicals, Inc., Costa Mesa, CA), then filtered through a sterile gauze. The PBMCs were isolated using Ficoll-Hypaque density gradient centrifugation (EuroBio S.A., Les Ulis, France). CD8+ cell lines were obtained by immunomagnetic purification of PBMCs with antiCD8-coated immunobeads (Dynal A.S., Oslo, Norway). Effector cells were incubated in round-bottomed 96-well plates (Costar Corp., Cambridge, MA) with $5 \times 10^{4} / \mathrm{ml} \mathrm{5,000} \mathrm{rads} \gamma$-irradiated autologous PBMCs previously stimulated overnight with $1 \mu \mathrm{g} / \mathrm{ml}$ phytohemagglutinin (PHA; Murex Diagnostics, Dartford, UK), in RPMI medium supplemented with $10 \%$ human serum AB (SAB), $0.3 \mathrm{mg} / \mathrm{ml}$ glutamine, $1 \mathrm{mM}$ sodium pyruvate, $100 \mathrm{U} / \mathrm{ml}$ penicillin, and $100 \mu \mathrm{g} / \mathrm{ml}$ streptomycin (GIBCO BRL, Cergy-Pontoise, France). Cell lines were maintained at $37^{\circ} \mathrm{C}$ in a humidified atmosphere of $5 \% \mathrm{CO}_{2}$. Recombinant human IL-2 (20 IU/ml; Boehringer Mannheim) was added at days 3, 9, and 15, and CTL responses were tested at day 21.

Human HLA typing. HLA class I and II transplantation antigens were defined serologically using a standard complement-mediated microcytotoxicity assay. The typing of class II antigens was further confirmed using RFLP procedures.

Cytotoxicity assays. Target cells were labeled with $\mathrm{Na}_{2}{ }^{51} \mathrm{CrO}_{4}$ (Amersham International, Les Ulis, France) at $80 \mu \mathrm{Ci} / 10^{6}$ cells. Suspensions of $4 \times 10^{3}$ target cells were added in triplicate to microtiter plates before addition of effector cells at various $\mathrm{E} / \mathrm{T}$ ratios. After a 4-h incubation period at $37^{\circ} \mathrm{C}$, the supernatants were harvested, and the chromium release was measured in a $\gamma$ counter (Clinigamma; ECG Instruments, Evry, France). Spontaneous ${ }^{51} \mathrm{Cr}$ release values were $15-25 \%$ of the total incorporated radioactivity. The percentage of specific ${ }^{51} \mathrm{Cr}$ release was calculated as follows: $100 \times($ experimental release - spontaneous release)/(total release - spontaneous release).

\section{Results}

Phenotype of skin-infiltrating cells in HIV-infected patients presenting with the cutaneous pseudolymphoma. Using immunohistological analysis, cells infiltrating the dermis and/or epidermis of the four patients were shown to be comprised of $>90 \%$ $\mathrm{CD} 2+\mathrm{CD} 3+\mathrm{TCR} \alpha \beta+$ cells (Fig. 2), expressing exclusively CD8 (17). In patient $\mathrm{A}, \sim 30 \%$ of these CD8+ cells were stained by the mAb S6F1, which reacts with the cytotoxic $\mathrm{T}$ cell subset (6). In all cases, the proportion of CD25+ cells among skin-infiltrating lymphocytes (SILs) was $<5 \%$ (data not shown). Immunostaining analysis with a panel of anti-BV mAbs in patient A showed that $\sim 20 \%$ of SILs were stained with an anti-BV8 (Fig. 2), whereas only $4 \%$ of CD8+ PBMCs were shown to be BV8+ by double-staining immunofluorescence analysis (Table II). Immunostaining of the lymph node biopsy taken from patient $\mathrm{A}$ showed a $\mathrm{T}$ cell infiltration of the interfollicular areas composed of CD4+ and CD8+ cells (Fig. $3, A$ and $B$ ). Interestingly, BV8+ lymphocytes were also observed, representing $\sim 10 \%$ of the lymph node $\mathrm{T}$ cell infiltrate, and HIV-1 p24+ cells were detected, some of them localized in the vicinity of $\mathrm{CD} 8+$ cells (Fig. 3, $C$ and $D$ ). Immuno- 

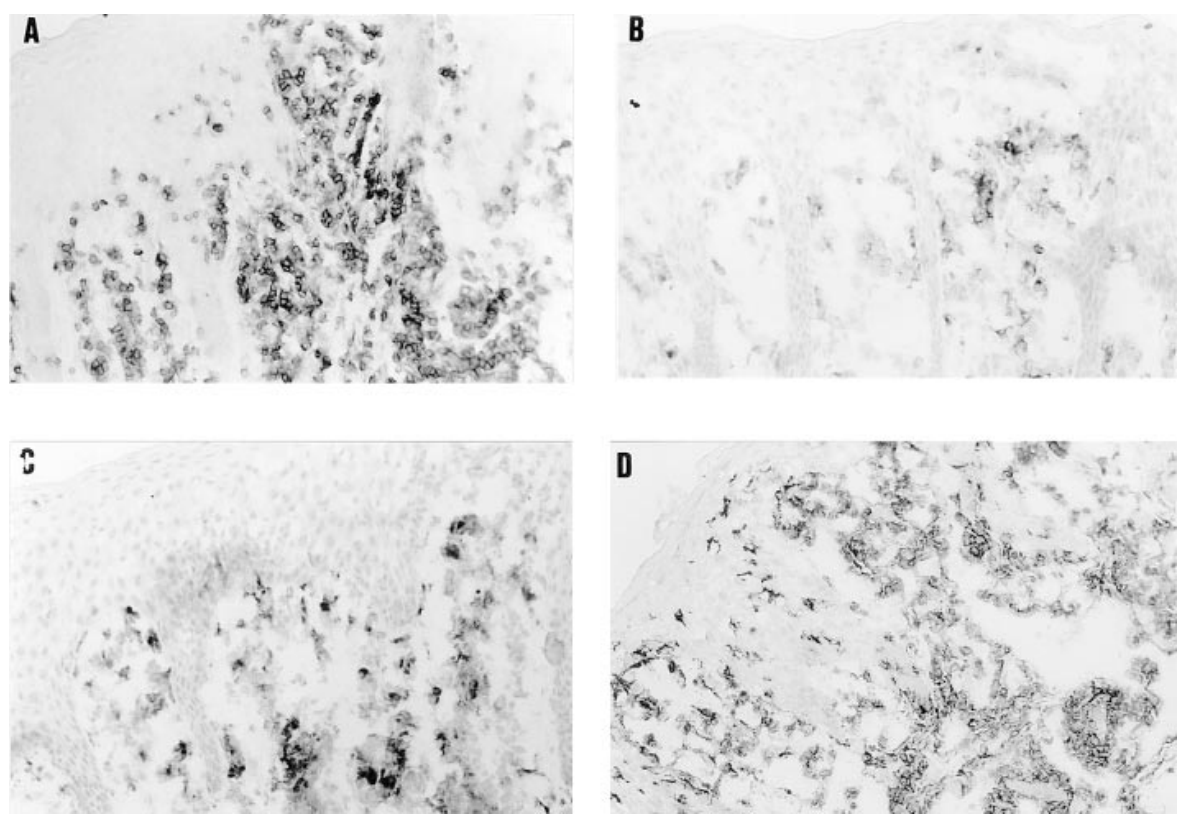

Figure 2. Frozen tissue sections from skin lesions of patient $\mathrm{A}$, stained with either anti-CD3 mAb $(A)$, anti-BV8 $\mathrm{mAb}(B)$, anti-S6F1 mAb $(C)$, or anti-CLA mAb $(D)$ and counterstained with hematoxylin. Most of the dermal and epidermal infiltrating $\mathrm{T}$ cells are $\mathrm{CD} 3+\mathrm{CLA}+$.

staining with HECA-452 $\mathrm{mAb}$, which reacts with the skinhoming receptor CLA (32), was performed on the lesional skin and on PBMCs from patient A. The results showed that all SILs expressed CLA (Fig. 2 D), whereas in the blood, CLA expression was predominant in the CD8+ cell subset (Table II). Furthermore, cytofluorometric analysis of PBMC subsets from four HIV-infected patients without skin symptoms showed that the mean proportion of blood lymphocytes coexpressing CLA and CD8 was far below that found in patient A (1.8 vs. $16 \%$, respectively) (Table II).

Skin-infiltrating CD8+ T cells use a restricted set of TCRBV gene segments. To determine whether an antigenic stimulation could be involved in the recruitment, activation, and expansion of CD8+ cells in the skin rash occurring during the course of
HIV infection, we looked for a preferential use of particular TCRBV segments by the SILs in four patients affected by this cutaneous disorder. We compared the TCRBV repertoire used in SILs and in CD8+ PBMCs by semiquantitative PCR analysis of TCR $\beta$ transcripts belonging to the 24 TCRBV families. As shown in Table III, comparison of the TCRBV repertoires from the skin and blood of each patient established that particular BV segments were used preferentially by infiltrating cutaneous lymphocytes. In patient A, BV2 and BV16 transcripts are twice as abundant in the skin, compared with blood; BV6 and BV8 transcripts were also overrepresented in the skin. Similarly, a bias towards BV16 expression was found in SILs from patient $\mathrm{B}$, whereas transcripts belonging to that family were not predominantly amplified from normal skin
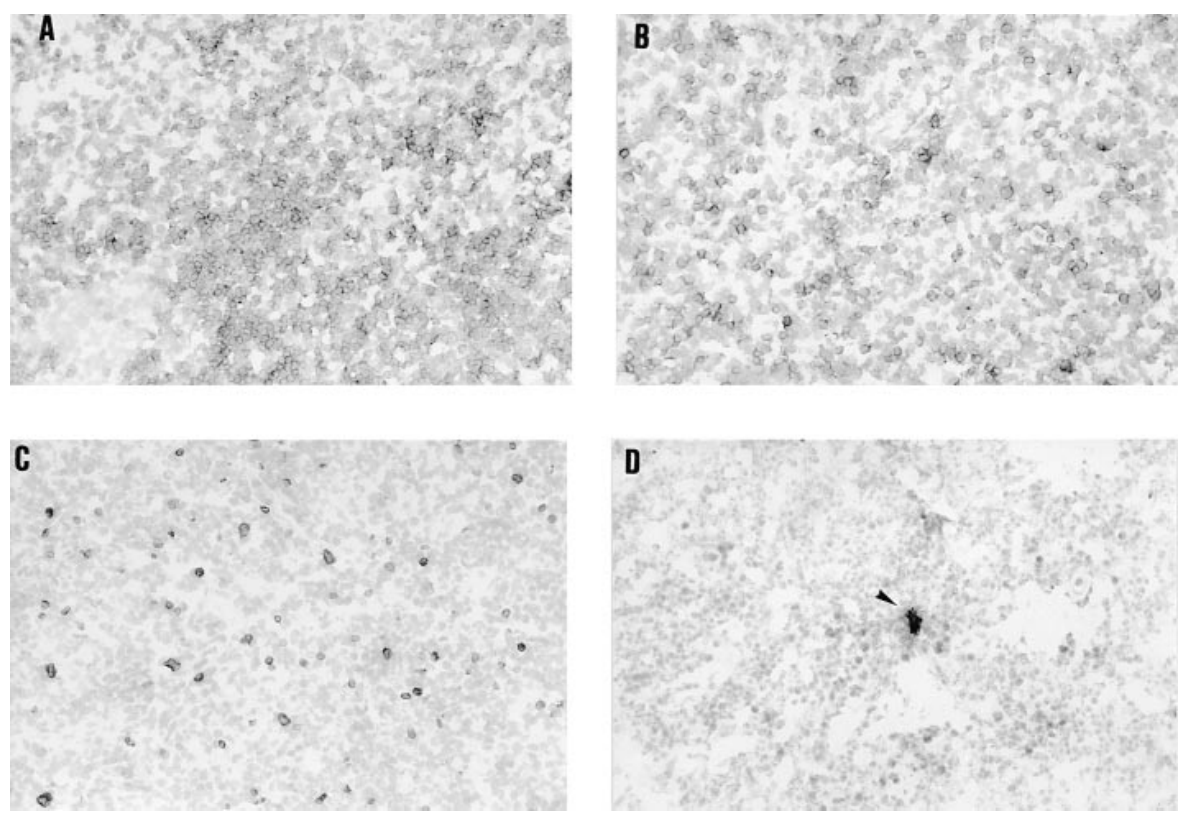

Figure 3. Frozen tissue sections from the cervical lymph node biopsy performed in patient $\mathrm{A}$. Immunostaining with anti-CD8 $\mathrm{mAb}(A)$, anti-CD4 $\mathrm{mAb}(B)$, anti-BV8 $(C)$, or anti-HIV p24 $(D)$. p24-stained cells (arrow) are present in the interfollicular area, which is infiltrated by $\mathrm{T}$ lymphocytes that are predominantly CD $8+$. 
Table II. Immunostaining Analysis of CLA Expression Among CD4+ and CD8+ PBMCs of Patient A, and of Four $H I V$-infected Patients without Skin Symptoms

\begin{tabular}{|c|c|c|c|c|c|c|}
\hline \multirow[b]{2}{*}{ Patient } & \multicolumn{2}{|c|}{ PBMC counts } & \multicolumn{4}{|c|}{ Percentage of blood lymphocytes expressing* } \\
\hline & $\mathrm{CD} 4$ & CD8 & $\mathrm{CD} 4+$ & $\mathrm{CD} 8+$ & $\mathrm{CD} 4+\mathrm{CLA}+$ & $\mathrm{CD} 8+\mathrm{CLA}+$ \\
\hline & cells/ $\mu l$ & cells/ $\mu l$ & & & & \\
\hline A & 450 & 1800 & 17 & 56 & 1.7 & 16 \\
\hline $\mathrm{G}^{\ddagger}$ & 123 & 560 & 11.8 & 60.3 & 0.97 & 0.59 \\
\hline $\mathrm{H}^{\ddagger}$ & 139 & 529 & 17.5 & 63.55 & 0.64 & 0.77 \\
\hline $\mathrm{I}^{\ddagger}$ & 185 & 554 & 18.8 & 57 & 1.51 & 1.77 \\
\hline $\mathrm{J}^{\ddagger}$ & 312 & 540 & 25.1 & 54.2 & 0.9 & 3.10 \\
\hline
\end{tabular}

*Results are obtained by flow cytometry analysis of PBMCs after double immunostaining with a PE-conjugated anti-CD8 or anti-CD4 mAb and with an FITC-conjugated anti-CLA mAb; expressed as a percentage of all gated lymphocytes. ${ }^{\ddagger}$ Patients G, H, I, and J are four HIVseropositive individuals devoid of any skin disease at the time of the study.

Table III. Percentage of BV Gene Expression in SILs and CD8+ PBMCs from HIV-infected Patients with a Chronic Cutaneous Disorder

\begin{tabular}{|c|c|c|c|c|c|c|c|c|c|c|}
\hline \multirow{3}{*}{$\begin{array}{l}\text { BV } \\
\text { family }\end{array}$} & \multicolumn{10}{|c|}{ Patients } \\
\hline & \multicolumn{3}{|c|}{ A } & \multicolumn{2}{|c|}{ B } & \multicolumn{3}{|c|}{$\mathrm{C}$} & \multicolumn{2}{|c|}{ D } \\
\hline & SIL1 & SIL2 & PBMC & SIL & PBMC & SIL1 & SIL2 & PBMC & SIL & PBI \\
\hline 1 & 11 & 5.9 & 10 & 5.8 & 11.9 & 5.4 & 6.8 & 3.7 & 3.3 & 5.6 \\
\hline 2 & $13.8^{*}$ & $14.7^{*}$ & 6.6 & 10.5 & 15 & 5.4 & 7.8 & 5.1 & $18.3^{*}$ & 7 \\
\hline 3 & 2.1 & 4.4 & 8.2 & 5.8 & 10.1 & 1.8 & 6.8 & 6.9 & 4.2 & 5.3 \\
\hline 4 & 12.2 & 4.4 & 9.1 & 12.7 & 11 & 4.8 & $29.4 *$ & 5.5 & $18.3^{*}$ & 7.3 \\
\hline 5 & 7.8 & 4.9 & 2.2 & 3.4 & 11.6 & 9 & 5.9 & 5.5 & $16.6^{*}$ & 4.8 \\
\hline 6 & 10.2 & 12.2 & 11.9 & 0 & 5.8 & 9.6 & 6.8 & 18.4 & 8.3 & 8.4 \\
\hline 7 & 6 & 3.9 & 7.2 & 4.6 & 4.3 & 7.2 & 7.8 & 13.8 & 12.5 & 7 \\
\hline 8 & $14.8^{*}$ & 2.9 & 5.4 & 5.8 & 4.9 & $41 *$ & $19.6^{*}$ & 4.2 & 5 & 8.2 \\
\hline 9 & 2.4 & 4.9 & 3.4 & 0 & 2.3 & 0 & 0 & 0 & 0 & 4.2 \\
\hline 10 & 0.4 & 1.5 & 1.8 & 0 & 0 & 1.2 & 0 & 0 & 0 & 2.2 \\
\hline 11 & 0 & 1.5 & 3.6 & 0 & 0.9 & 1.8 & 0 & 4.6 & 0 & 3.7 \\
\hline 12 & 2.9 & 9.3 & 11.6 & 0 & 1.4 & 0 & 0 & 0 & 0 & 1.7 \\
\hline 13 & 0.2 & 2.4 & 1 & 0 & 0.4 & 1.8 & 0 & 0 & 0 & 1.4 \\
\hline 14 & 1 & $6.4^{*}$ & 1.3 & 0 & 1.7 & 2.4 & 0 & 0 & 1.7 & 0.6 \\
\hline 15 & 0.8 & 2.9 & 3.2 & 4.6 & 2.3 & 3 & 0 & 3.2 & 2.5 & 4.5 \\
\hline 16 & $8.6^{*}$ & 3.4 & 2.6 & $40.7^{*}$ & 3.8 & 1.8 & 0 & 3.2 & 1.7 & 4.2 \\
\hline 17 & 2.9 & 2.9 & 2.3 & 5.8 & 4.9 & 1.8 & 2.9 & 3.7 & 0 & 3.4 \\
\hline 18 & 0 & 0 & 0 & 0 & 0 & 0 & 0 & 0 & 0 & 0.6 \\
\hline 19 & 1.8 & 3.4 & 2.5 & 0 & 0 & 0 & 1.9 & 6 & 4.2 & 3.7 \\
\hline 20 & 0 & 0 & 0 & 0 & 1.6 & 0 & 0 & 2.4 & 2.5 & 1.4 \\
\hline 21 & 0 & 0 & 0 & 0 & 0 & 0 & 0 & 7.8 & 0 & 0 \\
\hline 22 & 0 & 2.4 & 0 & 0 & 0.4 & 0 & 0 & 4.2 & 1.7 & 5.3 \\
\hline 23 & 0.1 & 5.4 & 1.9 & 0 & 3.5 & 1.8 & 3.9 & 8.4 & 2.5 & 5.1 \\
\hline 24 & 0.5 & 0 & 0 & 0 & 2 & 0 & 0 & 0 & 0 & 4.2 \\
\hline
\end{tabular}

Results are expressed as the percentage of total BV PCR products, and are compared within the same patient between skin lymphocytes and CD8+ PBMCs. In patients A and C, two separate skin samples (SIL1 and SIL2) were analyzed. *Skin values at least twice as large as the corresponding ones in paired PBMCs. samples obtained in two HIV-seropositive asymptomatic individuals (Table IV). Among SILs from patient C, expression was skewed towards the BV8 family. In patients A and C, TCRBV transcripts were analyzed in skin samples taken from anatomically distinct sites. Interestingly, striking changes in the relative expression of transcripts specific for particular BV families were evident from one area of affected skin to another in the same patient, as shown for the BV4 and BV8 subsets in patient $\mathrm{A}$, and for the BV4 subfamily in patient $\mathrm{C}$ (Table III).

Altogether, this first set of data strongly suggests a skinspecific homing and expansion of CD8+ $\mathrm{T}$ cells expressing particular TCRBV gene segments in HIV-infected patients with a lymphoinfiltrative disorder of the skin.

Oligoclonal nature of CD8+ SILs. BV-specific PCR only allows a low-resolution analysis of the TCR repertoire. Indeed, the fine antigenic specificity of the TCR is carried almost entirely by the CDR3 (33), which can vary by as many as eight residues between different TCR $\beta$ chains.

To address whether the CD8+ SILs in these HIV-infected patients could be involved in an antigen-specific immune response, we comparatively studied the TCRBV junctional diversity used by the SILs and by the PBMCs in the BV families that were found to be overrepresented in the SILs. It was observed with the so called "immunoscope" approach that BV-BC PCR products yield an average of eight peaks spaced

Table IV. Percentage of BV Gene Expression in Lymphocytes Infiltrating the Normal Skin (SIL) from Two Asymptomatic HIV-infected Control Patients

\begin{tabular}{lll}
\hline & \multicolumn{2}{c}{ Controls } \\
\cline { 2 - 3 } BV family & \multicolumn{1}{c}{$\mathrm{E}$} & $\mathrm{F}$ \\
\hline 1 & 10.2 & 8.4 \\
2 & 13 & 21.8 \\
3 & 7.6 & 23.1 \\
4 & 9.25 & 14.7 \\
5 & 7.1 & 7.5 \\
6 & 5.9 & 0 \\
7 & 8.8 & 4.2 \\
8 & 9.5 & 4.6 \\
9 & 2.4 & 1.2 \\
10 & 0.5 & 2.5 \\
11 & 0.7 & 2.1 \\
12 & 0.6 & 0 \\
13 & 0 & 0 \\
14 & 0.3 & 0.2 \\
15 & 6.6 & 7.1 \\
16 & 4.5 & 0.4 \\
17 & 5 & 0 \\
18 & 0 & 1.2 \\
19 & 1.9 & 0 \\
20 & 0 & 0 \\
21 & 0.9 & 0 \\
22 & 1.4 & 0.8 \\
23 & 0.2 & 0 \\
24 & & \\
& & \\
& &
\end{tabular}

Results are expressed as the percentage of total BV-BC PCR signals. 
by three nucleotides (corresponding to in-frame transcripts). Moreover, it was also shown that in normal PBMC samples, BV-BC size distribution profiles usually have Gaussian patterns that signify polyclonality, and are remarkably stable between control subjects over time (34). Conversely, a relative increase in the height of a particular peak that disrupts the Gaussian pattern by surfacing over polyclonal background usually corresponds to a clonal expansion, as has been demonstrated by direct sequence analysis of such "abnormal" peaks (34).

CDR3 size distribution analysis revealed the presence of few dominant peaks among patterns obtained from SILs, whereas the corresponding CD8+ PBMC profiles were more diverse (Fig. 4). Immunoscope analysis of SIL samples from patient A revealed the presence of two strikingly dominant peaks corresponding to TCR $\beta$ chains, characterized by their CDR3 lengths of eight and nine amino acids within the BV6 and BV16 subsets, respectively. As indicated in Fig. 4, dominant peak sizes were demonstrated within SIL TCR BV4 and TCR BV16-specific products from the skin of patient B, TCR BV4 and TCR BV8 from the skin of patient C, and TCR BV4 from the skin of patient D. Altogether, the TCR $\beta$ CDR3 size distribution patterns strongly suggest the oligoclonal nature of CD8+ T cells infiltrating the skin lesions. In patients A and C, skin biopsies were performed simultaneously at two separate sites of involved skin. Immunoscope analysis of TCR transcripts amplified from these samples revealed clear topographic differences in TCRBV repertoire used by SILs within the same individual. As shown in Fig. 4, SILs from patient A make use of totally dissimilar repertoires at distinct skin areas.
Although clear differences are also found in BV8 immunoscope profiles obtained from the two biopsies of patient $\mathrm{B}$, a similarly biased repertoire of BV4 gene segments was used by SILs from the same subject, in both areas.

Analysis of the TCRBV CDR3 sequences in the HIV-related skin disorder support an antigen-driven selective expansion of SILs. We cloned and sequenced the BV-BC PCR products obtained from blood and skin lesions of patient A, with oligonucleotides specific for TCRBV families BV2, BV6, BV8, and BV16, i.e., families found to be overexpressed in SILs. As shown in Table $\mathrm{V}$, there was a clearly biased use of the BJ2S1 segment within BV2 SILs in patient A, since eight of nine inframe BV2 rearrangements used the BJ2S1 segment, and three isolates showed an identical CDR3 amino acid sequence. Five additional clones exhibited a conserved glutamic acidglutamine motif (EQ) contributed by the BJ segment. In contrast, the five BV2 clones from the CD8+ PBMCs showed no redundant CDR3 DNA or amino acid sequence. Interestingly, all the sequences of BV2 CDR3 regions cloned from the blood were distinct from those derived from the SILs. In the same patient, the BJ2S7 segment was used by seven of eight BV6 clones derived from the SILs, six of them bearing an identical CDR3 including the EQ motif from the BJ segment. As expected from immunoscope analysis, the CDR3 of the dominant BV6 clone was six amino acids long (see Fig. 4, patient A, sample 1). However, all BV6 cDNA clones derived from the CD8 PBMCs were different, and displayed CDR3 sequences that were not found in the skin sample. Two clones appeared to dominate the BV8+ subset of the skin infiltrate. Finally, all BV16 sequences derived from SILs were identical, as expected
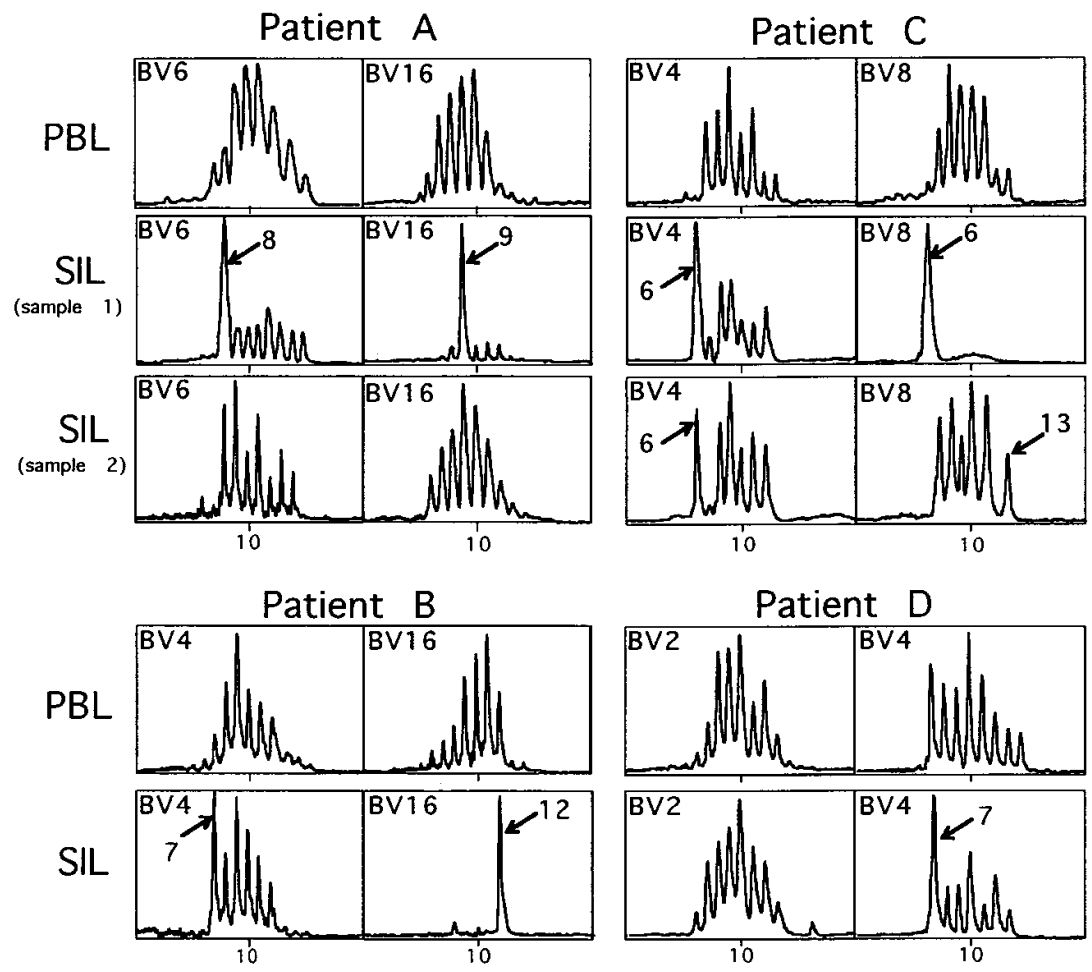

CDR3 Size (AA)
Figure 4. The SIL population is likely to be strongly oligoclonal and compartmentalized. Immunoscope profiles corresponding to BV families overexpressed in the skin (see Table III) are presented in comparison with those obtained from autologous CD8+ PBMCs. For each patient, two BV families were studied, and the corresponding $\mathrm{BV}$-specific primer used is indicated in the window of analysis. The CDR3 length of the major size peaks detected is indicated (arrow, and number of amino acid residues). Two separate skin samples (right and left abdominal flanks, sample 1 and sample 2, respectively) were studied in two cases. The graphs represent the intensity of fluorescence in arbitrary units, as a function of the CDR3 length, in amino acids $(A A)$, of BV-BC single-strand DNA runoff products. 
Table V. DNA Sequences of BV-BJ TCR Junctional Regions Cloned from PCR Products Obtained from Skin Samples (SIL) and from Purified CD8+ PBMCs of Patient A, and Predicted Amino Acid Sequences of the CDR3

\begin{tabular}{|c|c|c|c|c|c|c|c|}
\hline Source & $\mathrm{BV}$ & BJ & $\mathrm{V} \beta$ & CDR3 region & $\mathrm{J} \beta$ & CDR3 AA sequence & Frequency \\
\hline \multirow[t]{7}{*}{ SIL } & 2 & $2 \mathrm{~S} 1$ & TGCAGTGCT & AGAGATCACAGCGGGGCCTCTGGGAATGAGCAG & TTCTTCGGG & RDHSGASGNEQ & $3 / 9$ \\
\hline & 2 & $2 \mathrm{~S} 1$ & TGCAGTGCT & CTGATCATAAGCTCCTACAATGAGCAG & TTCTTCGGG & LIISSYNEQ & $1 / 9$ \\
\hline & 2 & $2 \mathrm{~S} 1$ & TGCAGTGCT & ATACCGGGACAAATCTACAATGAGCAG & TTCTTCGGG & IPGQIYNEQ & $1 / 9$ \\
\hline & 2 & $2 \mathrm{~S} 1$ & TGCAGTGCT & ACTCGTGAGACTAGCGGGGGGGGGGAGCAG & TTCTTCGGG & TRETSGGGEQ & $1 / 9$ \\
\hline & 2 & $2 \mathrm{~S} 2$ & TGCAGTGCG & CTCACCGGGGACAGGGAGCTGTACGGGGAGCTG & TTTTTTGGA & LTGDRELYGEL & $1 / 9$ \\
\hline & 2 & $2 \mathrm{~S} 1$ & TGCAGTGCT & AGAGAACCAACTAGCGGGAGGGCTATGGATGAGCAG & TTCTTCGGG & REPTSGRAMDEQ & $1 / 9$ \\
\hline & 2 & $2 \mathrm{~S} 1$ & TGCAGTGCT & AGGGACTGGCGGGAGCGGAGCTCCTACAAAGAGCAG & TTCTTCGGG & RDWRERSSYKEQ & $1 / 9$ \\
\hline \multirow[t]{5}{*}{ CD8 PBMC } & 2 & $2 \mathrm{~S} 3$ & TGCAGTGCG & CGGCTCCGGGCCCAAAGCACAGATACGCAG & TATTTTGGC & RLRAQSTDTQ & $1 / 5$ \\
\hline & 2 & $2 \mathrm{~S} 1$ & TGCAGTGCT & AACCTCCCCCCTGAGCAG & TTCTTCGGG & NLPPEQ & $1 / 5$ \\
\hline & 2 & $2 \mathrm{~S} 1$ & TGCAGTGCT & ACTCGTGAGACTAGCGGGGGGGGGAATGAGCAG & TTCTTCGGG & TRETSGGGNEQ & $1 / 5$ \\
\hline & 2 & $1 \mathrm{~S} 3$ & TGCAGTGCT & ACCCGGGACAGATTTGGAAACACC & TATTTTGGA & TRDRFGNT & $1 / 5$ \\
\hline & 2 & $2 \mathrm{~S} 1$ & TGCAGTGCT & AGAGATAAGGCTAGCGAGCTATACAATGAGCAG & TTCTTCGGG & REKASELYNEQ & $1 / 5$ \\
\hline \multirow[t]{3}{*}{ SIL } & 6 & $2 \mathrm{~S} 7$ & TGTGCCAGC & AGCTTAGGACAAGCCTACGAGCAG & TACTTCGGG & SLGQAYEQ & $6 / 8$ \\
\hline & 6 & $2 \mathrm{~S} 3$ & TGTGCCAGC & AGCTCGCAACTGACCGGGACTAGAGGGACAGATACGCAG & TATTTTGGC & SSQLTGTRGTDTQ & $1 / 8$ \\
\hline & 6 & $2 \mathrm{~S} 7$ & TGTGCCAGC & AGCGTTTCTGAACCGGAGCAG & TACTTCGGG & SVSEPEQ & $1 / 8$ \\
\hline \multirow[t]{4}{*}{ CD8 PBMC } & 6 & $2 \mathrm{~S} 1$ & TGTGCCAGC & AGCCAAGCGGCCGTCGGGACAGGGCTTTACAATGAGCAG & TTCTTCGGG & SQAAVGTGLYNEQ & $1 / 4$ \\
\hline & 6 & $2 \mathrm{~S} 3$ & TGTGCCAGC & AGCCAAGACCCCTCAGGTCATGAGCAG & TATTTTGGC & SQDPSGHEQ & $1 / 4$ \\
\hline & 6 & $2 \mathrm{~S} 1$ & TGTGCCAGC & AGCTTAGATAGCGGAGAAGGACCCTCCTACGAGCAG & TTCTTCGGG & SLDSGEGPSYEQ & $1 / 4$ \\
\hline & 6 & $2 \mathrm{~S} 5$ & TGTGCCAGC & AGCCTAAGAGGGAAAGACCAG & TACTTCGGG & SLRGKDQ & $1 / 4$ \\
\hline \multirow[t]{4}{*}{ SIL } & 8 & 2S5 & TGTGCCAGC & TCGCCGCTAGCGGGGAAAGAGACCCAG & TACTTCGGG & SPLAGKETQ & $1 / 10$ \\
\hline & 8 & 2S5 & TGTGCCAGC & AGCCTCCTTGTGGGGGGGCTTAAAGAGACCCAG & TACTTCGGG & SLLVGGLKETQ & $4 / 10$ \\
\hline & 8 & 1S5 & TGTGCCAGC & AGCTTCGGGGGGACGGGCAATCAGCCCCAG & CATTTTGGT & SFGGTGNQPQ & $4 / 10$ \\
\hline & 8 & $2 \mathrm{~S} 5$ & TGTGCCAGC & GGCCTGGGGGGGCGGCAGACCCAG & TACTTCGGG & GLGGRQTQ & $1 / 10$ \\
\hline SIL & 16 & $1 \mathrm{~S} 2$ & TGTGCCAGC & AGCCAAACAGGGGGCCTTCATGGCTAC & ACCTTCGGT & SQTGGLHGY & $4 / 4$ \\
\hline \multirow[t]{7}{*}{ CD8 PBMC } & 16 & $2 \mathrm{~S} 2$ & TGTGCCAGC & AGCCAAAGTCTC & TTTTTTGGA & SQSLTGEL & $1 / 7$ \\
\hline & 16 & $2 \mathrm{~S} 1$ & TGTGCCAGC & AGCCAAGGTGGTTACAATGAGCAG & TTCTTCGGG & SQGGYNEQ & $1 / 7$ \\
\hline & 16 & $2 \mathrm{~S} 1$ & TGTGCCAGC & AGCCAAGAGGTAGCCCAG & TTCTTCGGG & SQEVAQ & $1 / 7$ \\
\hline & 16 & 2S5 & TGTGCCAGC & AGCCAGGCGGGGGGCGGTGCAGAGACCCAG & TACTTCGGG & SQAGGGAETQ & $1 / 7$ \\
\hline & 16 & $2 \mathrm{~S} 3$ & TGTGCCAGC & AGCCCCGGGGGAGTGTCTTCAGCATACGCA & TATTTTGGC & SPGGVSSAYA & $1 / 7$ \\
\hline & 16 & 1S2 & TGTGCCAGC & AGCCAAGGGAACCTTATATGGCTACACCTT & ACCTTCGGT & SQGNLIWLHL & $1 / 7$ \\
\hline & 16 & $2 \mathrm{~S} 3$ & TGTGCCAGT & AGTGGGACAGGGGGCGCAGATACGCATATT & TATTTTGGC & SGTGGADTHI & $1 / 7$ \\
\hline
\end{tabular}

Sequences are available in GenBank under accession numbers Z95081-Z95112. AA, Amino acid. Redundant sequences, corresponding to clonal expansions, are in bold.

from immunoscope analysis of that subset (see Fig. 4, patient A, sample 1). In contrast, the BV16 PBMC clones sequenced were all different.

Thus, sequencing of the CDR3 regions confirmed the CDR3 dependence of the cutaneous T cell expansion.

Class I MHC-restricted cytotoxic recognition of HIV antigens by skin-derived CD8+ T cell lines. To test the ability of SILs to recognize and lyse target cells expressing HIV structural or regulatory protein-derived peptides, short-term CD8 $\mathrm{T}$ cell lines were generated from the SILs and PBMCs of patient A, and from the SILs of patient D. After allogenic stimulation and in vitro expansion in IL-2-containing medium for $4 \mathrm{wk}$, cytofluorometric analysis showed that $>90 \%$ of SILderived cell lines exhibited a CD3 + CD8+ CD4- phenotype (Fig. 5). We investigated the cytotoxic activity of these lines against autologous or allogenic B-LCL cells infected with vaccinia virus constructs expressing different HIV proteins. As shown in a previous preliminary report, the CD8 SIL-derived cell lines from patient $\mathrm{A}$ exhibited a strong lytic activity against autologous targets expressing Gag and Pol gene products, whereas anti-Nef cytotoxic activities appeared marginal (17). In contrast, HIV-1 Nef was shown to be recognized predominantly by CTL lines originating from the PBMCs of the same patient (Table VI). SIL lines derived from patient D were predominantly Env-specific, although a weak Pol-specific lytic activity was also detected (Fig. 6).

The class I MHC restriction of the HIV-specific lysis mediated by cutaneous lymphocytes was investigated. CTL lines derived from the skin of patient A efficiently lysed Pol-expressing allogeneic targets which shared the patient's HLA-B8 antigen, whereas they did not kill HLA-B-mismatched B-LCL infected with VAC-POL (Fig. $6 A$ ). In patient D, the SILderived CTL line was shown to be lytic against allogenic Envexpressing B-LCL 2226 sharing the patient's HLA-B72 specificity (Fig. $6 \mathrm{~B}$ ). This latter CTL line exerted no specific lysis when tested against the A23/B49 expressing B-LCL 2210, or when a totally class I-mismatched, DR11-expressing B-LCL was used as target. 
A
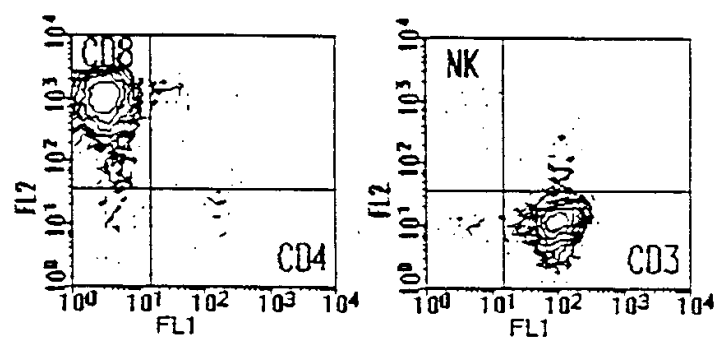

B
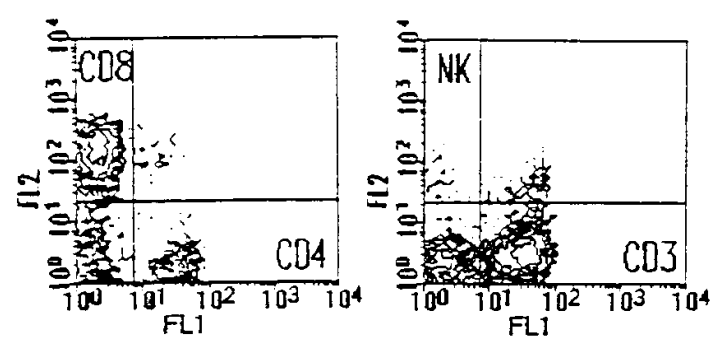

Figure 5. (A) Cytofluorometric analysis of the CTL line obtained from the SILs of patient A; $98 \%$ of the cells are CD3+CD8+ and do not express natural killer (NK) cell markers (CD56 and CD16). (B) Analysis of PBMCs from patient B; $82 \%$ of the cells are CD8+, $10 \%$ are $\mathrm{CD} 4+$, and $7 \%$ bear natural killer $(\mathrm{NK})$ cell markers.

Altogether, these results demonstrate that the CTL recognition of HIV gene products by SILs originating from patients A and D is restricted by HLA-B8 and HLA-B72 class I antigens, respectively.

In vitro-expanded SIL lines are representative of the skin infiltrate. To ascertain that functionally analyzed cell lines were representative of the skin infiltrate, we studied the TCRBV repertoire used by CTL lines generated from the SILs of patient A. As shown in Table VII, the cDNA sequence analysis of junctional regions expressed in the $\mathrm{T}$ cell lines was performed for the subsets that were not clonal in situ, i.e., BV2, BV6, and BV8. We were concerned that the polyclonal back-
Table VI. HIV-specific Cytotoxic Activities in CD8+ $T$ Lymphocytes Derived from the PBMCs of Patient $A$

\begin{tabular}{lcc}
\hline & \multicolumn{2}{c}{ Percentage of HIV-1-specific lysis* } \\
\cline { 2 - 3 } E/T ratio & HIV-1 Pol & HIV-1 Nef \\
\hline $30 / 1$ & 15 & 55 \\
$10 / 1$ & 2 & 38 \\
$3 / 1$ & 5 & 22
\end{tabular}

The predominant anti-Nef activity detected in the blood-derived CTL line contrasts with the strong anti-Pol CTL activity of a CTL line derived from the skin of the same patient (see Fig. 6). *Effector cells were tested against autologous EBV-transformed cell lines infected with VAC-POL, VAC-NEF, and VAC-WT as control.

ground might have been amplified artificially in vitro in such cases. CDR3 length analysis (not shown) and CDR3 sequencing of the BV segments used predominantly by one short-term CTL line revealed redundant rearrangements identical to those overexpressed in situ.

\section{Discussion}

The data presented here provide evidence for the infiltration of HIV-specific CTLs in the skin of HIV-infected patients affected by a severe skin disorder occurring years after a primary HIV infection. Results from previous studies indicated that patients presenting with this HIV-related chronic skin disorder demonstrate infiltration of both the dermis and epidermis by activated CD8+ T cells (17). Although histological examination of the lesional skin may reveal in some cases a dense infiltrate, cytonuclear irregularities are not consistently found, and no aberrant expression of T cell antigens by SILs can be found. Furthermore, molecular genetic studies did not show evidence for a dominant clonal rearrangement of the TCR loci (16-18). These preliminary data argued against a neoplastic $\mathrm{T}$ cell disorder, and we therefore postulated that a CD8 cell-mediated immune response against HIV antigens could be involved in the pathogenesis of this syndrome.

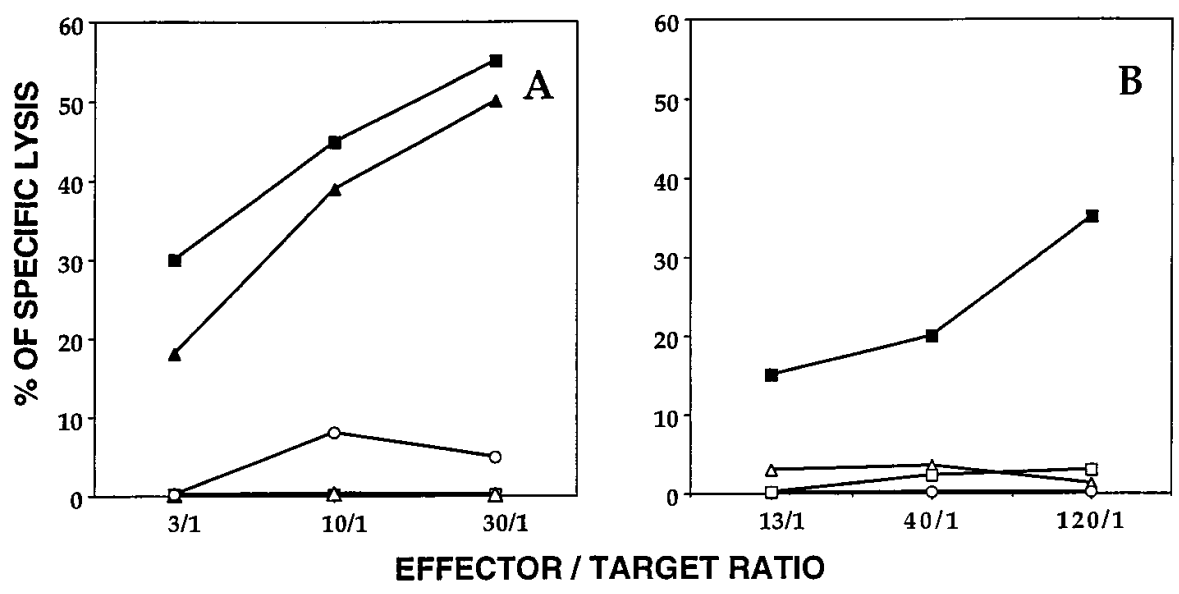
cells, all infected with VAC-ENV.

Figure 6. (A) The CD8 cell line derived from the SIL1 sample of patient A mediates specific and HLA-B8-restricted lysis of Pol-expressing target cells. Effector cells (HLA A1-A11/B8-B63/DR13-DR13) were tested against autologous (filled squares), HLA-A1/B8-sharing (filled triangles), HLA-A1-sharing (open squares), HLA-DR13-sharing (open triangles), and MHC-mismatched (open circles) (HLA A26(10)-A32/B55(22)-B44(12)/ DR4-DR5) B-LCL target cells, all infected with VAC-POL. $(B)$ The CD8 cell line from the SILs of patient D mediates specific and HLA-B72-restricted lysis of Envexpressing target cells. Effector cells (HLA-A23(9)-A/B49(21)-B72(70)/DR13DR11) were tested against HLA-B72-shar- 
Table VII. Sequences of BV-BJ TCR Junctional Regions Cloned from PCR Products Obtained from a CD8 CTL Line Derived from the Lesional Skin of Patient A, and Predicted Amino Acid Sequences of the CDR3 Region

\begin{tabular}{|c|c|c|c|c|c|c|c|}
\hline Source & BV & BJ & $\mathrm{V} \beta$ & CDR3 region & $\mathrm{J} \beta$ & CDR3 AA sequence & Frequency \\
\hline \multirow[t]{3}{*}{ SIL line } & 2 & $2 \mathrm{~S} 1$ & TGCAGTGCT & AGAGATCACAGCGGGGCCTCTGGGAATGAGCAG & TTCTTCGGG & RDHSGASGNEQ & $6 / 8$ \\
\hline & 2 & $2 \mathrm{~S} 1$ & TGCAGTGCT & AGAGAACCAACTAGCGGGAGGGCTATGGATGAGCAG & TTCTTCGGG & REPTSGRAMDEQ & 1/8 \\
\hline & 2 & $1 \mathrm{~S} 1$ & TGCAGTGCT & AACTACAAGCCCCGACAGGGAGGCACTGATGCT & TTCTTTGGA & NYKPRQGGTDA & $1 / 8$ \\
\hline SIL line & 6 & $2 \mathrm{~S} 7$ & TGTGCCAGC & AGCTTAGGACAAGCCTACGAGCAG & TACTTCGGG & SLGQAYEQ & $5 / 5$ \\
\hline \multirow[t]{2}{*}{ SIL line } & 8 & $2 \mathrm{~S} 5$ & TGTGCCAGC & AGCCTCCTTGTGGGGGGGCTTAAAGAGACCCAG & TACTTCGGG & SLLVGGLKETQ & $2 / 4$ \\
\hline & 8 & 1S5 & TGTGCCAGC & AGCTTCGGGGGGACGGGCAATCAGCCCCAG & CATTTTGGT & SFGGTGNQPQ & $2 / 4$ \\
\hline
\end{tabular}

Sequences are available in GenBank under accession numbers Z95081-Z95112. Sequences found previously in SILs before in vito culture are in bold. $A A$, Amino acid.

In the first part of this report, we investigated in four patients the diversity of the TCRBV repertoires used by SILs and by CD8 PBMCs. When the repertoires from blood and lesional skin samples were compared within the same patient using semiquantitative BV-specific RT-PCR, striking differences were observed. Particular BV transcripts appeared to be relatively more abundant in samples derived from skin lesions. Although some BV subsets were found to be overexpressed in the SILs from several patients, such as BV2 in patients A and $\mathrm{D}$ and BV16 in patients $\mathrm{A}$ and $\mathrm{B}$, no common BV expression profile was demonstrated in all patients, suggesting that the skin-homing CD8 expansion was not related to a common superantigenic stimulation. Furthermore, since the results from in situ immunostaining analysis using a restricted set of antiBV mAbs provided results that were correlated with those obtained by PCR analysis, it is likely that the increased levels of particular BV transcripts do not simply reflect a specific activation, but also result from a preferential proliferation of CD8 $\mathrm{T}$ cells expressing these BV segments. Since all patients presented with a generalized erythroderma, normal skin was not available for comparative analysis from the same individual. However, the most represented BV subsets within the SILs from the patients were not predominant either in the normal skin from two HIV-seropositive individuals (Table IV) or in normal human skin as reported previously (35), indicating that a nonspecific expansion of skin-resident CD8 cells was unlikely to account for this cutaneous lymphoinfiltrative process.

We investigated more accurately the $\mathrm{T}$ cell diversity within the SILs and PBMCs of the four patients using the immunoscope approach. This method has been used previously to characterize in vivo the limited heterogeneity of the TCR $\beta$ repertoire used in a CD8 cell-mediated primary immune response in mice (36), whereas in humans, a similar approach allowed the detection of oligoclonal patterns of HIV-specific CTLs in the spleens of HIV-infected patients (11). In the four patients studied here, immunoscope profiles of the most represented BV subsets in the SILs displayed oligoclonal profiles, usually clearly distinct from those obtained from blood. However, a few identical peaks were also found in the CD8 PBMCs, suggesting a recirculation of skin-homing CD8 cells (see Fig. 4, patient 4, BV4). The oligoclonal nature of the skin infiltration was further confirmed by sequencing of the TCR $\beta$ junctional regions cloned from the SILs and from the PBMC compartments in patient $\mathrm{A}$. Indeed, the redundant use of CDR3 amino acid sequences within the BV2, BV6, BV8, and BV16 subsets was highly suggestive of an antigen-driven ex- pansion of CD8 cells bearing these BV segments in the skin lesions, and argues against a superantigenic stimulation (37). In $\mathrm{HIV}$-infected patients, a restricted repertoire of BV segments has been documented in the HIV-specific CTL expansion in the blood after primary infection (5), and among the $\mathrm{CD} 8+\mathrm{T}$ cell infiltration of the salivary glands in the HIVrelated Sicca syndrome (38).

The potent HIV Gag- and Pol-specific lytic function exhibited by SILs from patient $\mathrm{A}$ when tested at low $\mathrm{E} / \mathrm{T}$ ratio suggests a high frequency of HIV-specific CTL precursors within the skin infiltrate. The relatively lower level of Env-specific lysis displayed by the SILs from patient D is consistent with the decrease of HIV-specific CTL activity observed during the progression towards AIDS (39). Besides those quantitative differences, our results suggest that immunodominant HIV antigens differ from one patient to another. The comparative analysis of the TCRBV repertoire expressed in vivo and after in vitro expansion confirmed that CTL lines were representative of the cutaneous $T$ cell infiltration and did not originate from contaminating blood lymphocytes. Most CDR3 rearrangements that were overrepresented in the SIL lines and in the skin infiltrate were not found among the cloned BV sequences originating from the corresponding CD8 PBMCs.

Altogether, TCR $\beta$ repertoire studies and cytotoxicity assays strongly suggest that HIV-specific CTLs might be implicated in the pathogenesis of this inflammatory cutaneous disorder. Nevertheless, we cannot rule out the existence of additional CTL specificities in the skin infiltrate of the affected patients. In any case, our results raise the issue of the cellular target of the in vivo CTL response. An increasing body of evidence provided in vitro (40) and in vivo (41) indicate that epidermal Langerhans cells (LCs) can be productively infected by HIV-1. Like dendritic cells, which present antigen-derived peptides to CD8+ CTLs in a class I MHC-restricted fashion (42), LCs could play the role of antigen-presenting cells involved in the activation of CTLs during HIV infection. The detection of Pol-specific mRNA in the epidermal tissue sampled in patient $\mathrm{A}$ by the suction blister technique supports this latter hypothesis, whereas HIV RNA was not detected in the skin biopsies using in situ hybridization (data not shown). A preferential replication in LCs of a particular HIV-1 subtype might explain the predominant infiltration of the skin observed in these patients. However, such a mechanism is not supported by in situ immunohistochemical studies performed in patient A, showing no immunoreactivity of the skin biopsy with the anti-HIV-1 p24 mAb, whereas p24 antigen was detected in the 
lymph node biopsy. Therefore, it appears that there was no preferential HIV replication in the skin of patient A. It is much more likely that the predominant location of the CD8 infiltrate in the skin is related to the preferential expression of CLA within the CD8 $\mathrm{T}$ cell subset, as described previously in CTCLs (43). However, these data do not rule out the pathogenic role of a low level of HIV replication in the skin of these patients, since a sustained production of HIV-derived peptides in dendritic cells might lead to the chronic activation of HIVspecific CTLs among the CLA+ cells that are homing in the skin. The question still remains as to how CLA is upregulated in vivo.

The spatial variability of the BV repertoire used by SILs derived from two patients suggests a compartmentalization of the immune response. Similar topographic changes in the TCRBV repertoire have been found in the CTL infiltration of the splenic white pulp of AIDS patients presenting with thrombocytopenia (11). Since a topographic heterogeneity of HIV quasispecies has also been evidenced in the normal skin of an HIV-infected patient (44), various HIV CTL epitopes might be expressed differentially in distinct skin areas (45). Thus, HIV variability could explain in part the heterogeneous local recruitment of T cells that we have documented. Studies are in progress to address this hypothesis.

Although specific CTLs are probably critical in the control of HIV spreading after primary infection, recent data indicate that tissue infiltration by virus-specific CTLs might also contribute to the immunopathogenesis of various sequelae emerging during the course of HIV infection. The presence of HIVspecific CTLs has been demonstrated in the lungs of patients with lymphocytic alveolitis (6) and in the splenic white pulp of patients with splenomegaly and thrombocytopenia (11). Our data corroborate the results of previous work on the skin eruption that follows experimental infection of macaque rhesus monkey with SIV. Viral RNA was not detected in the skin of the animals by in situ hybridization, but only by PCR (15), as in the case of patient A in our study. In the animal model, both dermis and epidermis are infiltrated by activated CD8 T cells exhibiting SIV Gag-, Env-, and Pol-specific lytic activity (15). Therefore, although the skin viral burden might not be very high in the SIV model, viral antigens can nevertheless be presented efficiently in the skin. Both studies support the view that the skin might be a major site of interaction between HIV and the CTL response. Transgenic mice containing an HIV-1 provirus show a tissue-dependent level of transgene expression, the skin being one of the preferential sites of HIV-1 mRNA expression (46). Thus, organ-specific manifestations of AIDS might be explained partly by the existence of tissue-specific factors important in HIV-1 transcriptional and posttranscriptional regulation that could qualitatively affect the local expression of antigens.

In a recent study, HIV-specific CTLs could be detected in the genital mucosa of $63 \%$ of the HIV-infected women tested (47). It remains to be determined whether HIV-specific CTLs also infiltrate the normal skin of HIV-infected patients, where they might be involved on a regular basis in the elimination of infected LCs and skin-homing CD4 T cells.

\section{Acknowledgments}

We would like to thank Professor François Sigaux for his support with genetic molecular studies and discussions, Professor Philippe
Kourilsky and Dr. Christophe Pannetier for providing the Immunoscope software package and fluorescent oligonucleotides specific for the human J $\beta$ genes, Drs. Colette Raffoux, Virginia Lepage, and Ioannis Theodorou for HLA typing, Dr. Céleste Lebbé for clinical assistance, and Professor Brigitte Autran for helpful discussions and critical reading of the manuscript.

This work was supported by grants from La Fondation pour la Recherche Médicale (Sidaction, 1996).

\section{References}

1. Moskophidis, D., F. Lechner, H. Pircher, and R.M. Zinkernagel. 1993. Virus persistence in acutely infected immunocompetent mice by exhaustion of antiviral cytotoxic effector T cells. Nature. 362:758-761.

2. Yap, K.L., G.L. Ada, and I.F.C. McKensie. 1978. Transfer of cytotoxic T lymphocytes protect mice inoculated with influenza virus. Nature. 273:238-239.

3. Cannon, M.J., P.J.M. Openshaw, and B.A. Askonas. 1988. Cytotoxic T cells clear virus but augment lung pathology in mice infected with respiratory syncytial virus. J. Exp. Med. 168:1163-1168.

4. McMichael, A.J., F.M. Gotch, G.R. Noble, and P.A.S. Beare. 1983. Cytotoxic T-cell immunity to influenza. N. Engl. J. Med. 309:13-17.

5. Pantaleo, G., J.F. Demarest, H. Soudeyns, C. Graziosi, F. Denis, J.W. Adelsberger, P. Borrow, M.S. Saag, G.M. Shaw, R.P. Sekaly, and A.S. Fauci. 1994. Major expansion of CD8+ T cells with a predominant V $\beta$ usage during the primary immune response to HIV. Nature. 370:463-467.

6. Plata, F., B. Autran, L. Pedroza Martins, S. Wain-Hobson, M. Raphael, C. Mayaud, M. Denis, J.M. Guillon, and P. Debré. 1987. AIDS virus-specific cytotoxic T lymphocytes in lung disorders. Nature. 328:348-351.

7. Walker, B.D., S. Chakrabarti, B. Moss, T.J. Paradis, T. Flin, A.G. Durno, R.S. Blumberg, J.C. Kaplan, M.S. Hirsch, and R.T. Schooley. 1987. HIV specific cytotoxic T lymphocytes in seropositive individuals. Nature. 328:345-348.

8. Nixon, D.F., A.R.M. Townsend, F.G. Elvin, C.R. Rizza, J. Gallway, and A.J. McMichael. 1988. HIV-1 gag specific cytotoxic T lymphocytes defined with recombinant vaccinia virus and synthetic peptides. Nature. 336:484-487.

9. Hadida, F., G. Haas, N. Zimmermann, A. Hosmalin, R. Spohn, A. Samri, G. Jung, P. Debré, and B. Autran. 1995. CTLs from lymphoid organs recognize an optimal HLA-A2-restricted and HLA-B52-restricted nonapeptide and several epitopes in the C-terminal region of HIV-1 Nef. J. Immunol. 154:41744186.

10. Hadida, F., A. Parrot, M.P. Kieny, B. Sadat-Sowti, C. Mayaud, P. Debré, and B. Autran. 1992. Carboxy-terminal and central regions of human immunodeficiency virus-1 NEF recognized by cytotoxic T lymphocytes from lymphoid organs. An in vitro limiting dilution analysis. J. Clin. Invest. 89:53-60.

11. Cheynier, R., S. Henrichwark, F. Hadida, E. Pelletier, E. Oksenhendler, B. Autran, and S. Wain-Hobson. 1994. HIV and T cell expansion in splenic white pulps is accompanied by infiltration of HIV-specific cytotoxic T lymphocytes. Cell. 78:373-387.

12. Nowak, M.A., and C.R.M. Bangham. 1996. Population dynamics of immune responses to persistent viruses. Science. 272:74-79.

13. Buchmeier, M.J., R.M. Welsh, F.J. Dutko, and M.B.A. Oldstone. 1980 The virology and immunobiology of lymphocyte choriomeningitis virus infection. Adv. Immunol. 30:275-331.

14. Bertoletti, A., C. Ferrari, F. Fiaccadori, A. Penna, R. Margolskee, H.J. Schlicht, P. Fowler, S. Guilhot, and F.V. Chisari. 1991. HLA class I restricted human cytotoxic T cells recognize endogenously synthesized hepatitis B virus nucleocapsid antigen. Proc. Natl. Acad. Sci. USA. 88:10445-10449.

15. Yamamoto, H., D.J. Ringler, M.D. Miller, Y. Yasutomi, T. Hasunuma, and N.L. Letvin. 1992. Simian immunodeficiency virus-specific cytotoxic T lymphocytes are present in the AIDS-associated skin rash in rhesus monkeys. $J$. Immunol. 149:728-734.

16. Janier, M., C. Katlama, B. Flageul, F. Valensi, I. Moulonguet, F. Sigaux, D. Dompmartin, and J. Civatte. 1989. The pseudo-Sezary syndrome with CD8 phenotype in a patient with the acquired immunodeficiency syndrome (AIDS). Ann. Intern. Med. 110:738-740.

17. Bachelez, H., F. Hadida, and G. Gorochov. 1996. Mycosis fungoïdes like disease with massive infiltration of the skin by HIV-specific, cytotoxic CD8+ T cells. N. Engl. J. Med. 335:61-62.

18. Zhang, P., L. Chiriboga, M. Jacobson, E. Marsh, P. Hennessey, R. Schinella, and H. Feiner. 1995. Mycosis fungoideslike T-cell cutaneous infiltrates in patients with HIV infection. Am. J. Dermatopathol. 17:29-35.

19. Diamandidou, E., P.R. Cohen, and R. Kuzrock. 1996. Mycosis fungoides and Sezary syndrome. Blood. 88:2385-2409.

20. Wood, G.S., R.M. Tung, A.C. Haeffner, C.F. Crooks, S. Liao, R. Orozco, H. Veelken, M.E. Kadin, H. Koh, P. Heald, R.L. Barnhill, and J. Sklar. 1994. Detection of clonal T-cell receptor $\gamma$ gene rearrangements in early mycosis fungoides/Sezary syndrome by polymerase chain reaction and denaturing gradient gel electrophoresis (PCR/DGGE). J. Investig. Dermatol. 103:34-41.

21. Bachelez, H., L. Bioul, B. Flageul, M. Baccard, I. Moulonguet-Michau, O. Verola, P. Morel, L. Dubertret, and F. Sigaux. 1995. Detection of clonal 
T-cell receptor $\gamma$ gene rearrangements with the use of the polymerase chain reaction in cutaneous lesions of mycosis fungoides and Sézary syndrome. Arch. Dermatol. 131:1027-1031.

22. Centers for Disease Control and Prevention. 1993. Revised classification system for HIV infection and expanded surveillance case definition for AIDS among adolescents and adults. Morb. Mortal. Wkly. Rep. 41:1-19.

23. Van der Putte, S.C.J., J. Toonstra, D.F. Van Wichen, J.A.M. Van Unnick, and W.A. Van Vloten. 1988. Aberrant immunophenotypes in mycosis fungoides. Arch. Dermatol. 124:373-380.

24. Genevée, C., A. Diu, J. Nierat, A. Caignard, P.Y. Dietrich, L. Ferradini, S. Roman-Roman, F. Triebel, and T. Hercend. 1992. An experimentally validated panel of subfamily-specific oligonucleotide primers (V $\alpha 1-w 29 / V \beta 1-w 24)$ for the study of human $\mathrm{T}$ cell receptor variable $\mathrm{V}$ gene segment usage by polymerase chain reaction. Eur. J. Immunol. 22:1261-1269.

25. Chomczynski, P., and N. Sacchi. 1987. Single-step method of RNA isolation by acid guanidinium thiocyanate-phenol-chloroform extraction. Anal. Biochem. 162:156-159.

26. Choi, Y., B. Kotzin, L. Herron, J. Callahan, P. Marrack, and J. Kappler. 1989. Interaction of Staphylococcus aureus toxin "superantigens" with human T cells. Proc. Natl. Acad. Sci. USA. 86:8941-8945.

27. Gorochov, G., P. Debré, V. Leblond, B. Sadat-Sowti, F. Sigaux, and B. Autran. 1994. Oligo-clonal expansion of CD8+CD57+ T cells with restricted TCR $\beta$ chain variability after bone marrow transplantation. Blood. 83:587-595.

28. Kabat, E.A., T.T. Wu, H.M. Perry, K.S. Gottesman, and C. Foeller. 1991. Sequences of Proteins of Immunological Interest. United States Department of Health and Human Services, Public Health Service, National Institutes of Health, Bethesda.

29. Guy, B., M.P. Kieny, Y. Riviere, C. Le Peuch, K. Dott, M. Girard, L. Montagnier, and J.P. Lecoq. 1987. HIV F/3'orf encodes a phosphorylated GTP binding protein resembling an oncogene product. Nature. 330:266-269.

30. Rautmann, G., M.P. Kieny, R. Braudely, K. Dott, M. Girard, L. Montagnier, and J.P. Lecoq. 1989. HIV-1 core protein expressed from recombinant vaccinia viruses. AIDS Res. Hum. Retroviruses. 5:147-157.

31. Foster, C.A., H. Yokozeki, K. Rappersberger, F. Koning, B. VolePlatzer, A. Rieger, J.E. Coligan, K. Wolff, and G. Stingl. 1990. Human epidermal $\mathrm{T}$ cells belong to the lineage expressing alpha/beta T cell receptor. J. Exp. Med. 171:997-1013.

32. Picker, L.J., S.A. Michie, L.S. Rott, and E.C. Butcher. 1990. A unique phenotype of skin-associated lymphocytes in humans. Preferential expression of the HECA-452 epitope by benign and malignant $\mathrm{T}$ cells at cutaneous sites. Am. J. Pathol. 136:1053-1068.

33. Jorgensen, J.L., U. Esser, B. Fazekas de St. Groth, P.A. Reay, and M.M. Davis. 1992. Mapping T-cell receptor-peptide contacts by variant peptide immunization of single-chain transgenics. Nature. 355:224-230.

34. Pannetier, C., J. Even, and P. Kourilsky. 1995. T cell repertoire diversity and clonal expansions in normal and clinical samples. Immunol. Today. 16:176180.
35. Dunn, D.A., A.S. Gadenne, S. Swarnalatha, E.A. Lerner, M. Bigby, and P. Bleicher. 1993. T-cell receptor BV expression in normal human skin. Proc. Natl. Acad. Sci. USA. 90:1267-1271.

36. MacDonald, H.R., J.L. Casanova, J.C. Maryanski, and J.C. Cerottini. 1993. Oligoclonal expansion of major histocompatibility complex class I-restricted cytolytic T lymphocytes during a primary immune response in vivo: direct monitoring by flow cytometry and polymerase chain reaction. J. Exp. Med. 177: 1487-1492.

37. Musette, P., A. Galelli, P. Truffa-Bachi, W. Peumans, P. Kourilsky, and G. Gachelin. 1996. The J $\beta$ segment of the T cell receptor contributes to the V $\beta$ specific T cell expansion caused by staphylococcal enterotoxin B and Urtica dioica superantigens. Eur. J. Immunol. 26:618-622.

38. Dwyer, E., S. Itescu, and R. Winchester. 1993. Characterization of the primary structure of $\mathrm{T}$ cell receptor $\beta$ chains in cells infiltrating the salivary gland in the sicca syndrome of HIV-1 infection. J. Clin. Invest. 92:495-502.

39. Carmichael, A., X. Jin, P. Sissons, and L. Borysiewicz. 1993. Quantitative analysis of the human immunodeficiency virus type 1 (HIV-1)-specific cytotoxic T lymphocyte (CTL) response at different stages of HIV-1 infection: differential CTL responses to HIV-1 and Epstein-Barr virus in late disease. $J$. Exp. Med. 177:249-256.

40. Pope, M., M.G.H. Betjes, N. Romani, H. Hirmand, P.U. Cameron, L. Hoffman, S. Gezelter, G. Schuler, and R.M. Steinman. 1994. Conjugates of dendritic cells and memory $\mathrm{T}$ lymphocytes from skin facilitate productive infection with HIV-1. Cell. 78:389-398.

41. Henry, M., A. Uthman, C. Ballaun, G. Stingl, and E. Tschachler. 1994 Epidermal Langerhans cells of AIDS patients express HIV-1 regulatory and structural genes. J. Investig. Dermatol. 103:593-596.

42. Bevan, M.J. 1995. Antigen presentation to cytotoxic T lymphocytes in vivo. J. Exp. Med. 182:639-641.

43. Heald, P.W., S.L. Yan, R.L. Edelson, R. Tigelaar, and L. Picker. 1993. Skin-selective lymphocyte homing mechanisms in the pathogenesis of leukemic cutaneous T-cell lymphoma. J. Investig. Dermatol. 101:222-226.

44. Sala, M., G. Zambruno, J.P. Vartanian, A. Marconi, U. Bertazzoni, and S. Wain-Hobson. 1994. Spatial discontinuities in human immunodeficiency virus type 1 quasispecies derived from epidermal Langerhans cells of an AIDS patient and evidence for double infection. J. Virol. 68:5280-5283.

45. Nowak, M.A., R.M. May, R.E. Phillips, S. Rowland-Jones, D.G. Lalloo, S. McAdam, P. Klenerman, B. Köppe, K. Sigmund, C.R.M. Bangham, and A.J. McMichael. 1995. Antigenic oscillations and shifting immunodominance in HIV-1 infections. Nature. 375:606-611.

46. Bruggeman, L.A., M.M. Thomson, P.J. Nelson, J.B. Kopp, J. Rappaport, P.E. Klotman, and M.J. McElrath. 1994. Patterns of HIV-1 mRNA expression in transgenic mice are tissue dependent. Virology. 202:940-948.

47. Musey, L., Y. Hu, L. Eckert, M. Christensen, T. Karchmer, and M.J. McElrath. 1997. HIV-1 induces cytotoxic T lymphocytes in the cervix of infected women. J. Exp. Med. 185:293-303. 